\title{
BM] Global Health Key success factors of Mauritius in the fight against COVID-19
}

\author{
Laurent Musango, ${ }^{1}$ Lovena Veerapa-Mangroo, ${ }^{2}$ Zouber Joomaye, ${ }^{3}$ \\ Adarshini Ghurbhurrun, ${ }^{4}$ Vinoda Vythelingam, ${ }^{1}$ Elisabeth Paul (i) ${ }^{5}$
}

To cite: Musango $L$,

Veerapa-Mangroo L, Joomaye Z, et al. Key success factors of Mauritius in the fight against COVID-19. BMJ Global Health 2021;6:e005372. doi:10.1136/ bmjgh-2021-005372

Handling editor Seye Abimbola

Received 12 February 2021 Revised 25 February 2021 Accepted 1 March 2021

Check for updates

(c) Author(s) (or their employer(s)) 2021. Re-use permitted under CC BY-NC. No commercial re-use. See rights and permissions. Published by BMJ.

${ }^{1}$ World Health Organization Country Office for Mauritius, Port-Louis, Mauritius

${ }^{2}$ Ministry of Health and Wellness, Port-Louis, Mauritius ${ }^{3}$ Senior Adviser to the Prime Minister in Mauritius, Port-Louis, Mauritius

${ }^{4}$ Independent Consultant, PortLouis, Mauritius

${ }^{5}$ Department of Health Policies and Systems - International Heath, School of Public Health, Université Libre de Bruxelles, Brussels, Belgium

Correspondence to

Dr Elisabeth Paul;

Elisabeth.Paul@ulb.ac.be

\section{INTRODUCTION}

Mauritius is an island state in the Indian Ocean located within the continent of Africa, categorised as an upper-middle-income economy. It has an estimated population of 1.27 million inhabitants, a gross domestic product (GDP) of US $\$ 12.2$ billion and a per capita GDP of US\$ 9630 in $2021 .{ }^{1}$

Following the declaration of the COVID-19 outbreak as a public health emergency of international concern on 30 January 2020, the WHO requested member states to develop a National Strategic Plan for Preparedness and Response to the Outbreak with nine strategic pillars. ${ }^{2}$ Mauritius was identified as the country with the highest risk of exposure in the African Region, and South Africa, Cameroon and Algeria were the only large countries among the top 10 highest risk of exposure. ${ }^{3}$ Using a mathematical model, stratified by age, to predict the evolution of COVID-19 epidemics, some authors predicted a median symptomatic attack rate of as much as $42 \%$ in Mauritius over the first 12 months, if the epidemics was unmitigated. ${ }^{4}$

The first three COVID-19 cases (all imported) were detected in Mauritius on 18 March 2020. On 19 March, the borders were closed. With the escalation of cases, a curfew was imposed on $20 \mathrm{March}$, and eventually a complete lockdown was implemented on 24 March. ${ }^{5}$ According to the national surveillance system, the outbreak quickly evolved from sporadic cases to clusters and then to local transmission and was contained on 26 April 2020, after 39 days, with no locally transmitted cases until November 2020. Then, two new community cases were reported, and since 26 November, only imported cases have been reported in the island. The measures adopted by Mauritius have highly been praised by international organisations. ${ }^{6}$

Countries around the world have experienced very different epidemic profiles, with contextual factors, including social and
Summary box

The COVID-19 response in Mauritius, which is viewed as a success story, benefited from strong leadership, highest political engagement, and strong involvement of the WHO, the private sector and other key stakeholders.

- Another key success factor lies in clear, transparent and consistent communication, including feedback mechanisms to understand public perception, the result of which is good adherence by the population.

- Public health measures (quarantine, contact tracing, case investigation and isolation of contacts, mass testing) have also contributed to the success of the country in the fight against COVID-19.

- The Mauritian success story can be inspiring for other countries, especially regarding the importance of adapting measures to evolving knowledge and developing a clear and consistent communication policy so as to buy the adherence of the population.

- However, contextual factors (an island has a limited number of entry points) have also facilitated the implementation and success of these measures.

- Not all countries can expect similar results by copypasting the Mauritian response strategy and should probably adopt a comprehensive policy acting on various factors to fight the pandemic.

environmental factors, playing an important role in shaping the outcomes ${ }^{7}$-hence the importance of shaping response policies to local contexts ${ }^{8}$ and of adapting policies and interventions in light of emerging knowledge (evidence-based policy-making), engaging in transparent dialogues with stakeholders and developing appropriate communication strategies that build public trust and support. ${ }^{9}$ The purpose of this article is to analyse the success factors of Mauritius that could inspire other countries-if properly adapted to their context-in future outbreaks.

This article adopts a reflexive analytical approach to comprehend the key success factors of Mauritius in fighting the COVID-19 pandemic. Reflexivity can indeed be defined 'as an intentional intellectual activity in which 


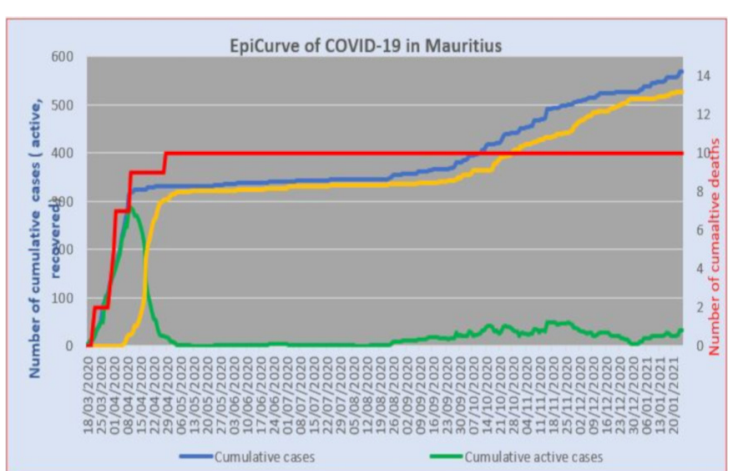

Figure 1 Cumulative cases and cumulated deaths, Mauritius, 18 March 2020 to 20 January 2021 (WHO COVID-19 Weekly Situation Report ${ }^{11}$ ).

individuals explore or examine a situation, an issue or a particular object on the basis of their past experiences to develop new understandings that will ultimately influence their actions'. ${ }^{10}$ Data were collected through participative observation of key stakeholders involved in the fight against the COVID-19 pandemic in Mauritius (WHO, Ministry of Health and Wellness) complemented by a targeted documentary and literature review. After presenting an overview of the evolution of the pandemic in Mauritius, we present a number of key factors that have emerged from our reflexive analysis as major contributors to explaining the success of Mauritius in the fight against COVID-19.

\section{OVERVIEW OF THE EVOLUTION OF THE PANDEMIC IN MAURITIUS}

As shown in figure 1, as of 17 January 2021, the cumulative number of confirmed COVID-19 cases was 556, of which 518 cases had successfully recovered, representing a recovery rate of $93.2 \%$. Among the 556 confirmed cases, $341(61.3 \%)$ were imported cases and $215(38.7 \%)$ emanated from local transmission. There were 10 deaths in total; the incidence was 4.4 per 10000 inhabitants and the case fatality rate was $1.8 \% .^{11}$

Table 1 compares the situation of Mauritius with selected countries of the Indian Ocean Island in terms of COVID-19 confirmed cases and deaths reported in the last 7 days by countries, territories and areas, as of 17 January 2021. It shows that Mauritius is the country/ territory that fares best in the Indian Ocean in terms of almost all indicators.

The key success factors identified are presented below.

\section{STRONG GOVERNANCE AND LEADERSHIP}

First, the COVID-19 response in Mauritius benefitted from strong leadership and highest political engagement. A High-Level COVID-19 Committee, chaired by the Prime Minister, was instituted on 31 January 2020 to monitor the local and international epidemiological situations and to rapidly share key information among the different ministries. The committee was composed of ministers in charge of Health and Wellness; Foreign Affairs, Regional Integration and International Trade; Finance, Economics, Planning and Development; Tourism; as well as the WHO Representative, the Secretary to Cabinet and Head of Civil Service, medical technical advisors and other key stakeholders. This whole-ofgovernment approach enabled a timely and informed decision-making for a coordinated and scaled-up national response. In addition to this, an intersectoral committee was established at the level of Ministry of Health and Wellness (MoHW), which monitored the evolution of the epidemiological situation as well as the daily activities related to the operational plan. It also elaborated guidelines and standard operating procedures when needed. Numerous protocols were devised for the different processes of case management, including transfer to intensive care unit, oxygenation, ventilation, discharge of recovered patients and taking charge of patients' family

Table 1 Comparison of Mauritius with neighbouring countries, selected COVID-19 indicators

\begin{tabular}{|c|c|c|c|c|c|c|c|}
\hline $\begin{array}{l}\text { Reporting } \\
\text { country/territory/ } \\
\text { area }\end{array}$ & $\begin{array}{l}\text { Cumulative } \\
\text { cases }\end{array}$ & $\begin{array}{l}\text { New } \\
\text { cases in } \\
\text { last } 7 \text { days }\end{array}$ & $\begin{array}{l}\text { Cumulative } \\
\text { cases per } \\
100000 \\
\text { population }\end{array}$ & $\begin{array}{l}\text { New deaths } \\
\text { in last } \\
7 \text { days }\end{array}$ & $\begin{array}{l}\text { Cumulative } \\
\text { deaths }\end{array}$ & $\begin{array}{l}\text { Cumulative } \\
\text { deaths per } \\
100000 \\
\text { population }\end{array}$ & $\begin{array}{l}\text { Transmission } \\
\text { classification }\end{array}$ \\
\hline Madagascar & 18001 & 234 & 65 & 5 & 267 & 1.0 & $\begin{array}{l}\text { Community } \\
\text { transmission }\end{array}$ \\
\hline Maldives & 14462 & 397 & 2675 & - & 49 & 9.1 & Clusters of cases \\
\hline Reunion & 9443 & 196 & 1055 & 3 & 45 & 5.0 & Clusters of cases \\
\hline Mayotte & 6611 & 379 & 2423 & 2 & 58 & 21.3 & Clusters of cases \\
\hline Comoros & 1577 & 427 & 181 & 23 & 41 & 4.7 & $\begin{array}{l}\text { Community } \\
\text { transmission }\end{array}$ \\
\hline Seychelles & 689 & 187 & 701 & - & 1 & 1.0 & $\begin{array}{l}\text { Community } \\
\text { transmission }\end{array}$ \\
\hline Mauritius & 547 & 8 & 43 & - & 10 & 0.8 & Clusters of cases \\
\hline
\end{tabular}

COVID-19 Weekly Epidemiological Update. ${ }^{11}$ 
members. Some of the protocols were the WHO protocols, whereas others were adapted to the local context, taking into consideration the capacities of the Mauritian healthcare system. Many of them were modified several times to adapt to the changes in resources and epidemiological context and integrate the lessons learnt.

The COVID-19 response also benefited from a strong involvement of the private sector. Business Mauritius, which represents over 1200 local businesses, and the Mauritius Chamber of Commerce coordinated actions with the Government. For instance, the Mauritius Chamber of Commerce facilitated the making of food packs distributed by the Ministry of Social Security to families on the Social Registrar of Mauritius, ensured food supply chain continuity and contributed to devising the Work Access Permit and the alphabetical order strategy for shopping during the lockdown.

It is also important to mention the pivotal support provided by the WHO Country Office since the discovery of the virus. This comprised the sharing and regular updating of key information and guidelines, and technical assistance to assess preparedness and strengthen the capacities of country's response to a health emergency, including the elaboration of the National Action Plan for Preparedness and Response. The WHO Country Office sustained its support, as the country prepared to start its vaccination campaign in January 2021. The purpose of 'national vaccine table top exercises' was to support country to plan, develop and update the national deployment and vaccination plan for COVID-19 vaccines, including testing and enhancing its planning assumptions. ${ }^{12}$ Moreover, the WHO Country Office provided technical advice as member of the High-Level Committee on COVID-19.

\section{CLEAR, TRANSPARENT AND CONSISTENT COMMUNICATION}

Another key success factor in the fight against the pandemic of COVID-19 lies in clear, transparent and consistent communication. Mauritius started with an early intense sensitisation campaign on COVID-19. As of 23 January 2020, the MoHW started a national sensitisation campaign through different media (radio, television and written press) and visuals (posters, pamphlets, banners and billboards), explaining the occurrence of the novel coronavirus, its mode of transmission, signs and symptoms, and preventive measures to be taken to avoid the infection. During total lockdown, the National Communication Committee held press briefings in camera to avoid contact and answered questions from independent journalists sent on a live platform put in place by the National Broadcaster. These early messages placed emphasis on physical distancing, use of face masks, hand hygiene and cough etiquette, and encouraged the public to call the hotline for further information or to signal suspected cases. Pamphlets were distributed at the port and airport; in educational institutions, community halls and centres at the level of town municipalities; in village and district councils; and in all health facilities.

Clear and consistent communication was facilitated by the creation of the National Communication Committee on COVID-19 as a unique, central communication mechanism. It is entitled to transmit decisions taken by the High-Level Committee on COVID-19 to the Mauritian population and to address the key issues during daily press briefings. In addition, members of the National Communication Committee on COVID-19 also participated in special live television programmes on COVID-19 on the national television and radio channels. These enable to provide more details on the different response measures and to answer questions raised by the general public. It has proven to be a very effective strategy to ensure an accurate, transparent and trustworthy stream of communication directly from the decision-makers to the general public and to reassure the population. To expand the dissemination of information on COVID-19 and to achieve a maximum reach, several media platforms were created: a website, http://www.COVID-19. $\mathrm{mu}$; a Facebook page 'Coronavirus Moris' dedicated to COVID-19 in Mauritius; and a mobile application, 'beSafeMoris'.

Communication goes both ways, and henceforth, several feedback mechanisms to understand public perception on COVID-19 were established-namely, a hotline dedicated to COVID-19, the monitoring of social media platforms and live radio shows, and regular feedback from the Mauritius Police Force and MoHW. These mechanisms helped to monitor the populations' behaviours with respect to the different measures implemented as well as their beliefs, fears and concerns which were consequently addressed during the regular press conference. As the outbreak progressed in Mauritius, the National Communication Committee on COVID-19 indeed observed that the population was more adherent to precautionary measures such as physical distancing and wearing masks while shopping and more respectful of the sanitary curfew in general. ${ }^{13}$

The National Communication Committee on COVID-19 also addressed rumours, misinformation and fake news with clear and correct clarifications with a view of halting their propagation. The committee condemned the spreading of fake news on social media-notably about the prevalence of COVID-19 cases in Mauritius, the number of deaths, the reliability of tests and treatments, and the reclosure of supermarkets-characterised such behaviour as antipatriotic and highlighted their negative impact such as installing a climate of fear or panic.

Last but not least, the government was also engaged to reassure the population that the country is COVIDsafe since 26 April 2020. The people were encouraged to remain alert and maintain recommended sanitary measures as the prevalence of COVID-19 is on the rise in foreign countries. This regular and transparent communication has proven to be highly effective. A considerable decrease in rumours and fake news was observed among 
the population and on social media. The population also reacted in a responsible and disciplined way when a cluster of two locally transmitted cases of COVID-19 were identified in November 2020. According to the reports from the COVID-19 testing centres, the Mauritius Police Force, media and social media, the population showed no behaviours expressing panic on the announcement of local cases. 'The population is now better prepared and when there is a local transmission they understand that the authorities took the needful measures did the contact tracing ... there was no panic, the population reacted responsibly and in discipline'-said Dr Joomaye Zouber, Senior Adviser to the Prime Minister in Mauritius, during his interview at the WHO Inter-Action Review exercise on 18 December 2020. There was also no indication of other behaviours such as panic buying and people not wanting to go to their workplace or sending their children to school.

\section{POPULATION ADHERENCE TO PHYSICAL DISTANCING MEASURES}

During the COVID-19 community transmission phase in March to May 2020, high-level governmental commitment and good communication resulted in strong adherence of the population to physical distancing measures in place. These include, for example, the fact that while supermarkets opened 6 days a week, Mauritians were only allowed to shop twice a week in alphabetical order using family names: A to F on Mondays and Thursdays, G to $\mathrm{N}$ on Tuesdays and Fridays, and $\mathrm{O}$ to $\mathrm{Z}$ on Wednesdays and Saturdays. One person per household was allowed to shop for $30 \mathrm{~min}$, and the wearing of protective masks was compulsory. Customers had to bring an identification document that was verified at the entrance of the supermarkets. The elderly, being more vulnerable, were dissuaded from shopping, whereas younger adults of the family were encouraged to do so. However, a special morning slot from 9:00 to 10:00 was created for elderly persons who had to shop for themselves. These measures were very well respected.

\section{STRONG PUBLIC HEALTH MEASURES}

Capitalising on decades of experience in successfully fighting communicable diseases, Mauritius' public health measures have also contributed to the success of the country in the fight against COVID-19. Contact tracing, case investigation and isolation of contacts were established under the supervision of the Communicable Diseases Control Unit. Once a positive COVID-19 case was notified by the Central Health Laboratory, the Communicable Diseases Control Unit contacted every person tested positive for case investigation following their transfer to the COVID-19 treatment centres. Key information about how long they had been sick, the people they stayed with, the people they had been in contact with and whether their contacts were sick, and the places they visited is collected. A list of all of the patient's contacts is elaborated, and each of them is contacted, asked for symptoms and instructed to self-isolate while waiting to be visited by the contact tracing team.

On 27 April 2020, a mass rapid testing campaign for COVID-19 targeting frontliners was initiated by the MoHW. By 7 July 2020, 160315 rapid tests were carried out among health personnel from both public and private institutions, including members of the police force, prison detainees, expatriates living in dormitories, pharmacies' personnel, scavenging and cleaning services, supermarkets personnel, personnel working for port and airport authorities, private sector staff, staff from various ministries, members of religious and sociocultural organisations, public transport workers and athletes, among others. This campaign was designed to ensure that there was no case of COVID-19 in Mauritius in preparation for the phased ease of lockdown. No positive case was subsequently found, and the testing campaign was stopped.

Laboratory testing has also been a priority from the start of the pandemic. The total number of tests conducted as of 17 January 2021 was 319 242, comprising 158927 PCR tests and 160315 rapid antigen tests. A 14-day quarantine is mandatory for those entering Mauritius, with entrance conditioned on the presentation of a negative PCR test 7 days before travel to Mauritius and three tests during the quarantine on day 1 , day 7 and day 14. All positive cases are treated in dedicated treatment centres until they get two consecutive negative tests at an interval of 24-48 hours. Mauritius is now elaborating the COVID-19 National Deployment and Vaccination Plan with a goal of re-opening borders.

\section{CONCLUSION}

On 19 January 2021, the High-Level Committee chaired by the Prime Minister met for the 101st time. It took note that while the number of cumulative cases compare with other African countries, the situation changed drastically because Mauritius, which was one of the most heavily hit African countries in April 2020, was the lowest affected country in the African region in January 2021. ${ }^{11}$

Like many other countries, Mauritius faced an unprecedented situation because it had never experienced a pandemic of that scale and responded promptly by actions initially taken on an ad hoc basis. However, the government learnt throughout the national response and improved its management of the pandemic accordingly. Overall, it is estimated that measures implemented to prevent widespread community transmission of COVID-19 may have saved the country 837 human lives worth international US\$258 080 991. This evidence, conjointly with human rights arguments, calls for increased investments to bridge the existing gaps for achieving universal health coverage by $2030 .^{14}$

We have identified governance and leadership, and communication, coupled with proactive contact tracing and test-and-treat measures as key factors contributing to the success of Mauritius. Other authors have also 
pinpointed the rapid response by the Mauritian Government, and appropriate and strong support and compliance from the public as key factors towards the control of the pandemic. ${ }^{5}$ A retrospective study using inferential statistical methods identified a number of factors that have contributed significantly in controlling the propagation of the novel coronavirus in Mauritius; in particular, the sanitary curfew/lockdown, sanitisation and sensitisation campaigns, and safe shopping guidelines have helped to curb down, by a large extent, the number of COVID-19 cases. Hence, such preventive and proactive measures, with the main focus on sanitisation measures at grocery stores and in busy public places, should be maintained even after lifting lockdown orders. Quarantine centres for all incoming passengers have also significantly helped in timely containment of the novel coronavirus, eliminating to a great extent the risk of spreading in the local community.

The Mauritian success story can be inspiring for other countries. However, it should be noted that contextual factors have also facilitated the implementation and success of these measures. The fact that Mauritius is an island, with a limited number of entry points, has obviously facilitated the identification of arriving persons and the follow-up of their quarantine. The fact that Mauritius is a close-knit society has also perhaps facilitated social control and adherence to governmental measures. Therefore, not all countries can expect similar results by copy-pasting the Mauritian response strategy-and most countries should probably adopt a comprehensive policy acting on complementary social, economic, physical and environmental factors to improve the health stock of the population and to curb the COVID-19 mortality. ${ }^{7}$ Nevertheless, Mauritius illustrates well the importance of adapting measures to evolving knowledge and developing a clear, transparent and consistent communication policy so as to buy the adherence of the population.

Contributors After analysis with all authors, LM wrote the first draft of this manuscript. EP contributed to framing the analysis and literature review. All authors contributed to revising the manuscript and approved the final version.

Competing interests Some authors are WHO staff or have received consultancy fees from WHO, and EP has conducted consultations for various international and donor agencies, but this article has been written in total independence from any funder.

Patient consent for publication Not required.

Provenance and peer review Not commissioned; externally peer reviewed.
Data availability statement Data are available in a public, open access repository.

Open access This is an open access article distributed in accordance with the Creative Commons Attribution Non Commercial (CC BY-NC 4.0) license, which permits others to distribute, remix, adapt, build upon this work non-commercially, and license their derivative works on different terms, provided the original work is properly cited, appropriate credit is given, any changes made indicated, and the use is non-commercial. See: http://creativecommons.org/licenses/by-nc/4.0/.

\section{ORCID iD}

Elisabeth Paul http://orcid.org/0000-0002-3928-4093

\section{REFERENCES}

1 International Monetary Fund. World economic outlook database, October 2020, 2020. Available: https://www.imf.org/en/Publications/ WEO/weo-database/2020/October

2 World Health Organization. COVID-19 strategic preparedness and response plan. Operational planning guidelines to support country preparedness and response, 2020. Available: https://extranet.who. int/sph/sites/default/files/document-library/document/srp-12022020. pdf

3 Cabore JW, Karamagi HC, Kipruto H, et al. The potential effects of widespread community transmission of SARS-CoV-2 infection in the world Health organization African region: a predictive model. BMJ Glob Health 2020;5:e002647.

4 van Zandvoort K, Jarvis CI, Pearson CAB, et al. Response strategies for COVID-19 epidemics in African settings: a mathematical modelling study. BMC Med 2020;18:324.

5 Kowlessur S, Ori B, Zimmet P, et al. Tackling the COVID-19 pandemic in paradise: the Mauritian experience. Lancet Diabetes Endocrinol 2020;8:878-9.

6 Mamode Khan N, Soobhug AD, Heenaye-Mamode Khan M. Studying the trend of the novel coronavirus series in Mauritius and its implications. PLoS One 2020;15:e0235730.

7 Ngepah N. Socio-Economic determinants of global COVID-19 mortalities: policy lessons for current and future pandemics. Health Policy Plan 2021. doi:10.1093/heapol/czaa161. [Epub ahead of print: 13 Jan 2021].

8 Eggo RM, Dawa J, Kucharski AJ, et al. The importance of local context in COVID-19 models. Nat Comput Sci 2021;1:6-8.

9 Paul E, Brown GW, Kalk A, et al. 'When My Information Changes, I Alter My Conclusions'. What Can We Learn from the Failures to Adaptively Respond to the SARS-Cov-2 Pandemic and the Under Preparedness of Health Systems to Manage COVID-19? Int J Health Policy Manag 2020.

10 Tremblay M-C, Richard L, Brousselle A, et al. Learning reflexively from a health promotion professional development program in Canada. Health Promot Int 2014;29:538-48.

11 World Health Organization. COVID-19 Weekly epidemiological update, 2021. Available: https://www.who.int/publications/m/item/ weekly-epidemiological-update-19-january-2021

12 World Health Organization. Coronavirus disease (COVID-19) training: simulation exercise, 2021. Available: https://www.who.int/ emergencies/diseases/novel-coronavirus-2019/training/simulationexercise

13 World Health Organization, Government of Mauritius. Best practices and experience of Mauritius' preparedness and response to COVID-19 pandemic, 2020. Available: https://www.afro. who.int/publications/best-practices-and-experience-mauritiuspreparedness-and-response-covid-19-pandemic

14 Musango L, Nundoochan A, Kirigia JM. The Discounted money value of human life losses associated with COVID-19 in Mauritius. Front. Public Health 2020;8:604394. 